\title{
Analysis of characteristics of peripheral arterial ischemia in premature babies and effects of nitroglycerin patch application
}

\author{
Jeongeun Kim ${ }^{1}$, Jin Won Lee ${ }^{1}$, Dong Yeon Kim ${ }^{2}$ \\ ${ }^{1}$ Registered Nurse, Neonatal Intensive Care Unit, Seoul St. Mary's Hospital, The Catholic University of Korea, Seoul; ${ }^{2}$ Unit Manager, Hematology Intensive Care \\ Unit, Seoul St. Mary's Hospital, The Catholic University of Korea, Seoul, Korea
}

Purpose: The aim of this retrospective study was to analyze the characteristics of peripheral arterial ischemia and tissue necrosis in premature babies, as well as the effects of nitroglycerin. Methods: In total, 513 newborns were enrolled who were admitted to the neonatal intensive care unit with a gestational age of 34 weeks or younger. Data were collected on general personal and clinical information, peripheral arterial ischemia, and nitroglycerin patch application in the premature infants. The collected data were analyzed using the $x^{2}$ test, t-test, Mann-Whitney U test, logistic regression. Results: Thirty-six (7.0\%) infants had peripheral arterial ischemia, while 477 (93.0\%) infants did not. Lower gestational age $\left(\chi^{2}=35.97, p<.001\right)$, lower birth weight $\left(\chi^{2}=29.40, p<.001\right)$, lower blood pressure $\left(x^{2}=23.10, p<.001\right)$, and insertion of an umbilical artery catheter $(p<.001)$ were significantly associated with the occurrence of peripheral arterial ischemia. Among the preterm infants in whom nitroglycerin patches were applied, $30(83.3 \%)$ premature infants without necrosis improved without complications, $4(11.1 \%)$ showed hypotension, and $2(5.6 \%)$ showed skin damage. Conclusion: Based on a review of our experiences with nitroglycerin patches, we recommend closely observing skin color and using nitroglycerin patches on the skin to help improve flow in premature infants with peripheral arterial ischemia.

Key words: Ischemia; Necrosis; Nitroglycerin; Therapeutic use; Transdermal patch

\section{Corresponding author Dong Yeon Kim \\ https://orcid.org/0000-0001-9500-5792}

Hematology Intensive Care Unit, Seoul St. Mary's Hospital, The Catholic University of Korea, 222 Banpo-daero, Seocho-gu, Seoul 06591, Korea

TEL +82-2-2258-5353 FAX +82-2-2258-6544

E-MAIL vonma98@naver.com

*This study was supported by the research fund of Seoul St. Mary's Hospital, the Catholic University of Korea in 2020.

Received Sep 6, 2020 Revised Sep 27, 2020 Accepted Sep 30, 2020
(9) This is an Open Access article distributed under the terms of the Creative Commons Attribution NonCommercial License (http://creativecommons.org/licenses/by-nc/4.0/) which permits unrestricted noncommercial use, distribution, and reproduction in any medium, provided the original work is properly cited.

\section{INTRODUCTION}

\section{Need for Study}

Microcirculation in newborns is very important in controlling tissue perfusion [1], and if the blood flow in the microcirculation of premature newborns is interrupted due to blood clots, embolism, or vasospasms, this will block the arteries and consequently damage the surrounding blood vessels and endodermis, causing skin tissue ischemia [2]. Peripheral arterial ischemia results in absent peripheral pulses, delayed capillary reperfusion time, decreased skin temperature, and skin discoloration, and it can also lead to a considerable loss of skin, hypodermis, and muscle [3]. Compared to full-term newborns, premature newborns (born at 34 weeks of gestation or younger) face heightened penetrability of external substances due to their thin epidermis, insufficient protein levels, and underdeveloped vernix. As a result, they face higher risks of loss of moisture, as well as infections and resulting morbidity $[3,4]$. In particular, premature newborns admitted to the neonatal intensive care unit (NICU) have small blood vessels and frequently require catheter insertion, leading to increased risks of poor circulation and blood clots [5]. Furthermore, blood clots are more likely to occur in premature newborns than in full-term newborns [6], so it is necessary to carefully inspect 


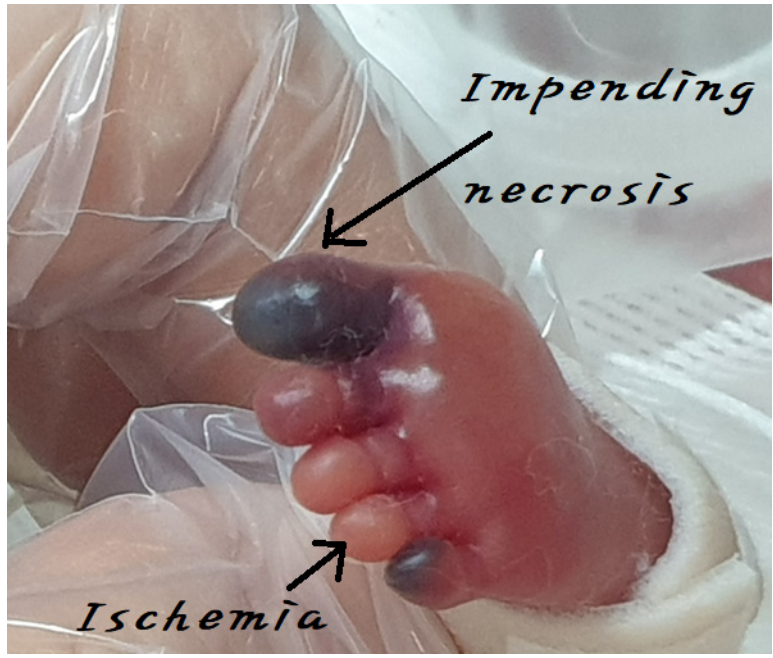

Figure 1. Impending necrosis and peripheral arterial ischemia.

their skin condition and symptoms of change in the peripheral tissues and to systematically treat areas affected by tissue ischemia and necrosis (Figure 1) [2].

Immediate and non-invasive methods of treating peripheral tissue ischemia and areas of necrosis include evaluating the need for catheters in blood vessels and removing them, elevating the limbs of the relevant areas, applying heating on the limb where thrombosis has not occurred, and performing soft massages $[2,5,7]$. However, some researchers, such as Samiee-Zafarghandy et al. [8] and Han et al. [9], reported that tissue ischemia and necrosis did not improve after implementing non-invasive treatment methods, meaning that these techniques have limitations in the treatment of peripheral tissue ischemia and necrosis. In contrast, nitroglycerin patches, anticoagulants, thrombolytic agents, and mechanical thrombectomy, which are also treatments for ischemia in newborns, are regarded as secondary treatment methods due to their high hemorrhage risks [5].

As an organic nitrate drug, nitroglycerin patches are used to treat skin tissue ischemia and necrosis because nitroglycerin expands blood vessels in arteries and veins, and local application of a nitroglycerin patch takes effect in vascular smooth muscles to immediately expand blood vessels and improve peripheral circulation [10-12]. Many earlier studies have applied nitroglycerin sprays or ointment as potential methods of treating peripheral arterial ischemia and necrosis in newborns $[2,5,8,11,13]$.

Nonetheless, few studies have implemented nitroglycerin treatment and investigated a diverse range of related factors in premature newborns with peripheral arterial ischemia or necrosis [5]. Moreover, few studies have investigated the effectiveness of treatment of necrosis using nitroglycerin patches as opposed to nitroglycerin ointment or sprays [2,8]. Nitro- glycerin patches are cheap and are distributed with a standard size; however, a single patch can be divided into multiple patches of various sizes, enabling it to be used more than once. As the nitroglycerin patch works locally, the side effects are low and the drug is effective [14].

Body temperature maintenance and skin care are important in the neonatal period. Insensible water loss, which refers to water loss that is not readily measured, involves evaporative losses through the skin (60\%-70\%) and the respiratory tract $(30 \%-40 \%)$. Almost two-thirds of water loss occurs through the skin in premature infants [12,15]. Based on the recommendations in the guidelines, covering and minimal handling of a premature baby with a warm blanket should be done at the time of admission to the NICU. However, this aspect of nursing care means that peripheral arterial ischemia may not be detected promptly. Nurses must be aware of the characteristics of peripheral arterial ischemia in order to provide adequate care to premature infants.

The goal of this study was to examine and analyze the incidence of peripheral arterial ischemia in premature newborns and the effects of applying nitroglycerin patches. By doing so, it aimed to establish a justification for skincare in nursing of premature newborns with peripheral tissue ischemia and necrosis, to promote the implementation of skincare protocols in clinical nursing, and thereby to contribute to nursing care for premature newborns.

\section{Purpose}

This study analyzed the characteristics that affected the incidence of peripheral arterial ischemia and tissue necrosis in premature newborns, as well as the effects of nitroglycerin patches. The specific objectives were as follows:

- To identify differences in the general characteristics of premature infants (and their mothers) with and without peripheral arterial ischemia.

- To identify differences in health status between premature newborns with and without peripheral arterial ischemia.

- To quantify the occurrence of necrosis in premature newborns with peripheral arterial ischemia

- To identify factors influencing the occurrence of peripheral arterial ischemia.

- To identify the effects of nitroglycerin patch application

\section{Definitions of Terms}

\section{1) Peripheral arterial ischemia}

Peripheral arterial ischemia occurs when blood flow is interrupted due to blood clots, embolism, or vasospasms; the re- 
sultant blockage of the arteries leads to damage of the surrounding blood vessels and endodermis, resulting in skin tissue ischemia [2]. When ischemia occurs, the skin is pale and white to the naked eye.

\section{2) Necrosis}

Necrosis refers to the decay or death of cells, typically because of blood flow problems such as ischemia, mechanistic injuries, chemical agents, or pathogens [16]. As necrosis progresses, the skin color begins to turn bluish or black.

\section{METHODS}

\section{Study Design}

This retrospective study analyzed the characteristics of peripheral arterial ischemia in premature newborns and the effectiveness of applying nitroglycerin patches.

\section{Subjects}

The subjects were collected from newborns at C University Hospital located in Seoul, South Korea, who were admitted to the neonatal intensive care unit after birth. The enrolled newborns were born at a gestational age of 34 weeks or younger between May 2016 and September 2019. The reason for conducting the study on preterm infants under 34 weeks of gestation is that these infants have anatomically and physiologically immature skin [17].

At the time of the investigation, data on 545 newborns existed, but data from three newborns who were transferred to the hospital 7 days after birth, one newborn with skin necrosis after birth, and 14 newborns who died on the day of birth were excluded. Data of 520 newborns were collected, in some of whom necrosis or ischemia occurred. After the exclusion of seven infants who had insufficient data because they died within 7 days, 513 were analyzed. Data were collected from two NICUs from a single institution, which reported data from 301 and 212 newborns, respectively. One NICU mainly provided care for micro-premature infants and the other NICU mainly had premature infants with surgical and cardiovascular problems.

\section{Study Tool}

\section{1) Nitroglycerin patches}

A doctor diagnosed peripheral arterial ischemia and necrosis, and gave the administration order for nitroglycerin patches (Angiderm patch, $0.2 \mathrm{mg} / \mathrm{hr}, 22.4 \mathrm{mg}$ ). A nurse cut a 5 $\times 10 \mathrm{~mm}$ piece and attached it to the lesion site.

\section{2) Case reports in Excel format}

A standardized data extraction tool in Excel was used. All data were input starting with the day of birth, and blood pressure and blood test results were analyzed based on regular blood tests on the third day after birth, when hemodynamic stability was achieved. Mean blood pressure was measured in the upper arm. Dionne et al. [18] created a reference table of normal blood pressure values in infants with post-conception ages between 26 and 44 weeks, which was used to analyze blood pressure in terms of percentiles. The collected data included information on 16 characteristics relevant to the study (e.g. general characteristics, hematology test results, treatment using ventilators, incidence of apnea. use of inotropic agents, insertion of umbilical or central venous catheters, incidence time of ischemia, area of incidence, application period of nitroglycerin patches, complications, prognosis, and incidence of necrosis).

\section{Data Collection}

This study was conducted after receiving approval (no. KC19RESI0656) from the Catholic University Medical Center (CMC) Institutional Review Board (IRB) in Seoul. Data was extracted using a clinical data warehouse and a neonatal register list. The three authors reviewed 520 electronic medical records (EMRs) from October 2019 to August 2020. Based on this review, seven newborns were excluded and 513 were investigated. As part of this retrospective study, the three co-researchers used EMRs to collect data on characteristics regarding patients' illnesses and clinical outcomes. Postnatal data collection points were uniformly unified, and the 50 data points were cross-checked by thee three authors. During cross-checking, disagreements were resolved by consensus of the authors. The investigated items did not display personal information, and additional personal information irrelevant to our research objectives, including patient registration number, patient name, and resident registration numbers were not recorded or saved.

\section{Data Analysis}

The collected data were analyzed using SPSS version 24.0 (IBM Corp., Armonk, NY, USA). The general characteristics of the premature infants (and their mothers) with and without peripheral arterial ischemia were analyzed using frequency, percentage, and the $x^{2}$ test, and tested using the Fisher exact test. Differences in the health status of premature newborns with or without peripheral arterial ischemia were analyzed using the average, standard deviation, and t-test. The occurrence of necrosis in premature newborns with pe- 
ripheral arterial ischemia was analyzed using the average, standard deviation, and the Mann-Whitney U test, and tested using the Fisher exact test. Factors influencing the occurrence of peripheral arterial ischemia were analyzed through univariate logistic regression. The effect of the nitroglycerin patch was analyzed in terms of frequency and percentage.

\section{RESULTS}

\section{General Characteristics of Premature Infants and Moth- ers with and without Peripheral Arterial Ischemia}

Of the 513 premature newborns, $36(7.0 \%)$ experienced peripheral arterial ischemia and 477 (93.0\%) did not. Birth weight and gestational age were classified according to skin maturity and temperature regulation [12]. The majority $(83.3 \%)$ of infants with peripheral arterial ischemia were born at 29 weeks or younger, reflecting a significant difference according to gestational age $\left(x^{2}=35.97, p<.001\right)$. Moreover, $22(61.1 \%)$ newborns with peripheral arterial ischemia weighed less than $1,000 \mathrm{~g}$, corresponding to a significant tendency for premature newborns with ischemia to have lower birth weight $\left(x^{2}=29.40\right.$, $p<.001)$. Premature newborns with ischemia were significantly more likely than those without ischemia to have polyhydramnios and oligohydramnios $(p=.038)$, patent ductus arteriosus $(p<.001)$, or pulmonary hypertension $(p<.001)$, and were also significantly more likely to die $(p<.001)$. The blood pressure of premature newborns with ischemia after 3 days of birth was significantly more likely to be in the lower 50 percentiles $\left(x^{2}=23.10, p<.001\right)$. There were also significant differences in the use of inotropic agents between the groups $\left(x^{2}=35.02, p<.001\right)$, as well as in the use of dopamine $\left(x^{2}=35.48\right.$, $p<.001)$, vasopressin $\left(x^{2}=48.17, p<.001\right)$, and epinephrine $(p<$ .001). Among the premature newborns who had catheters inserted at the time of ischemia, 16 (44.4\%) had umbilical arterial catheters, and insertion of an umbilical arterial catheter was significantly associated with ischemia $(p<.001)$ (Table 1$)$.

\section{Differences in the Health Status of Premature New- borns with or without Peripheral Arterial Ischemia}

Significant differences were found in the premature newborns' health status in terms of their Apgar scores and blood test results. Premature babies are not healthy babies, so their Apgar scores were not categorized; instead, the mean and standard deviation were calculated. The mean Apgar score at 1 minute was 2.61 in premature newborns with ischemia, while it was 4.23 in those without ischemia $(t=4.63, p<.001)$. The mean Apgar score at 5 minutes was 4.69 for premature newborns with ischemia, while it was 6.47 for those without ischemia ( $t=5.42, p<.001)$, indicating a lower score for newborns with ischemia. In addition, the premature newborns with ischemia had an average blood $\mathrm{pH}$ of 7.21 and those without ischemia had an average $\mathrm{pH}$ of $7.30(\mathrm{t}=4.90, p<.001)$. Premature newborns with ischemia had an average partial pressure of carbon dioxide $\left(\mathrm{CO}_{2}\right)$ in the blood of $53.24 \mathrm{mmHg}$ and those without ischemia had an average partial pressure of $\mathrm{CO}_{2}$ of $44.81 \mathrm{mmHg}(\mathrm{t}=3.02, p=.004)$, indicating that the blood test results for newborns with ischemia showed a higher level of $\mathrm{CO}_{2}$ retention. Premature newborns with ischemia had a base excess of $-6.19 \mathrm{mmol} / \mathrm{L}$ and those without ischemia had a base excess of $-4.22 \mathrm{mmol} / \mathrm{L}(\mathrm{t}=3.02, p=.003)$, showing that base excess was significantly lower in newborns with ischemia.

The results of blood tests at the third day after birth showed significant differences in hemoglobin levels and platelet count. Premature newborns with ischemia had an average hemoglobin level of $14.67 \mathrm{~g} / \mathrm{dL}$, while those without ischemia had an average hemoglobin level of $15.57 \mathrm{~g} / \mathrm{dL}(\mathrm{t}=1.99, p=.047)$. Premature newborns with ischemia had a platelet count of 182.56, while those without ischemia had a platelet count of $219.16(\mathrm{t}=2.96, p=.003)$. Additionally, premature newborns with ischemia had a creatine phosphokinase level of 152.47 $\mathrm{mg} / \mathrm{dL}$, while those without ischemia had a level of 218.59 $\mathrm{mg} / \mathrm{dL}(\mathrm{t}=2.07, p=.039)$. All of these values were lower in infants with ischemia.

The duration of inotropic agent use of premature newborns with ischemia was 8.89 days for dopamine ( $\mathrm{t}=5.48, p<.001)$, 4.81 days for vasopressin $(\mathrm{t}=3.83, p<.001)$, and 2.25 days for epinephrine $(t=2.53, p=.016)$; all of these periods were significantly longer (by two to four times) than in infants without ischemia.

The duration of ventilator use of premature newborns with ischemia within the first 7 days after birth was 6.39 days, which was more than twice as long as in those without ischemia $(t=9.97, p<.001)$. The average duration of umbilical arterial catheter use of premature newborns with ischemia was 4.22 days $(\mathrm{t}=3.55, p=.001)$, in sharp contrast to the duration of 0.44 days $(\mathrm{t}=3.94, p<.001)$ in those without ischemia (Table 2$)$.

\section{Occurrence of Necrosis in Premature Newborns with Peripheral Arterial Ischemia}

The average incidence date of ischemia was 3.15 days among the 36 newborns with ischemia, and the average incidence date of necrosis was 19 days among the newborns with ischemia who also developed necrosis, indicating a significant difference between the two groups ( $\mathrm{U}=66.0, p=.013$ ) (Table 3). Necrosis occurred on an average of 13 days after ischemia incidence in newborns. Nitroglycerin patches were 
Table 1. General Characteristics of Premature Infants with and without Peripheral Arterial Ischemia and Their Mothers $(N=513)$

\begin{tabular}{|c|c|c|c|c|c|c|c|}
\hline \multirow{3}{*}{ Variables } & \multirow{3}{*}{ Characteristics } & \multirow{3}{*}{ Categories } & \multirow{3}{*}{$\begin{array}{c}\text { Total } \\
\mathrm{n}(\%) \\
\end{array}$} & \multicolumn{2}{|c|}{ Peripheral arterial ischemia } & \multirow{3}{*}{$x^{2}$} & \multirow{3}{*}{$p$} \\
\hline & & & & \multirow{2}{*}{$\frac{\text { Yes }(n=36)}{n(\%)}$} & \multirow{2}{*}{$\begin{array}{c}\text { None }(\mathrm{n}=477) \\
\mathrm{n}(\%)\end{array}$} & & \\
\hline & & & & & & & \\
\hline \multirow[t]{39}{*}{ Newborn } & \multirow[t]{2}{*}{ Sex } & Male & $267(52.0)$ & $19(52.8)$ & $248(52.0)$ & \multirow[t]{2}{*}{0.01} & \multirow[t]{2}{*}{.927} \\
\hline & & Female & $246(48.0)$ & $17(47.2)$ & $229(48.0)$ & & \\
\hline & \multirow[t]{3}{*}{ Gestational age (week) } & $\leq 29$ & $192(37.4)$ & $30(83.3)$ & $162(34.0)$ & \multirow[t]{3}{*}{35.97} & \multirow[t]{3}{*}{$<.001$} \\
\hline & & $30-32$ & $194(37.8)$ & $6(16.7)$ & $188(39.4)$ & & \\
\hline & & $\geq 33$ & $127(24.8)$ & $0(0.0)$ & $127(26.6)$ & & \\
\hline & \multirow[t]{3}{*}{ Birth weight (g) } & $<1,000$ & $132(25.8)$ & $22(61.1)$ & $110(23.0)$ & \multirow[t]{3}{*}{29.40} & $<.001$ \\
\hline & & $1,000-1,800$ & $219(42.6)$ & $13(36.1)$ & $206(43.2)$ & & \\
\hline & & $>1,800$ & $162(31.6)$ & $1(2.8)$ & $161(33.8)$ & & \\
\hline & Place of birth & Inside born & $486(94.7)$ & $32(88.9)$ & $454(95.2)$ & - & $.112^{*}$ \\
\hline & & Outside born & $27(5.3)$ & $4(11.1)$ & $23(4.8)$ & & \\
\hline & Patent ductus arteriosus & None & $288(56.2)$ & $12(33.3)$ & $276(57.9)$ & - & $<.001^{*}$ \\
\hline & & No treatment & $140(27.3)$ & $12(33.3)$ & $128(26.8)$ & & \\
\hline & & Medication & $71(13.8)$ & $10(27.8)$ & $61(12.8)$ & & \\
\hline & & Operation & $14(2.7)$ & $2(5.6)$ & $12(2.5)$ & & \\
\hline & Persistent pulmonary & Yes & $54(10.5)$ & $14(38.9)$ & $40(8.4)$ & - & $<.001^{*}$ \\
\hline & hypertension & None & $459(89.5)$ & $22(61.1)$ & $437(91.6)$ & & \\
\hline & Death in hospital & Yes & $46(9.0)$ & $15(41.7)$ & $31(6.5)$ & - & $<.001^{*}$ \\
\hline & & None & $467(91.0)$ & $21(58.3)$ & $446(93.5)$ & & \\
\hline & MBP on the third day on birth & $<25$ th & $57(11.1)$ & $12(33.3)$ & $45(9.4)$ & 23.10 & $<.001$ \\
\hline & (mmHg, percentile) & 25 th- 49 th & $242(47.2)$ & $18(50.0)$ & $224(47.0)$ & & \\
\hline & & $\geq 50$ th & $214(41.7)$ & $6(16.7)$ & $208(43.6)$ & & \\
\hline & Inotropic agents & Yes & $149(29.0)$ & $26(72.2)$ & $123(25.8)$ & 35.02 & $<.001$ \\
\hline & & None & $364(71.0)$ & $10(27.8)$ & $354(74.2)$ & & \\
\hline & Dopamine & Yes & $148(28.8)$ & $26(72.2)$ & $122(25.6)$ & 35.48 & $<.001$ \\
\hline & & None & $365(71.2)$ & $10(27.8)$ & $355(74.4)$ & & \\
\hline & Vasopressin & Yes & $72(14.0)$ & $19(52.8)$ & $53(11.1)$ & 48.17 & $<.001$ \\
\hline & & None & $441(86.0)$ & $17(47.2)$ & $424(88.9)$ & & \\
\hline & Epinephrine & Yes & $43(8.4)$ & $12(33.3)$ & $31(6.5)$ & - & $<.001^{*}$ \\
\hline & & None & $470(91.6)$ & $24(66.7)$ & $446(93.5)$ & & \\
\hline & Norepinephrine & Yes & $10(1.9)$ & $0(0.0)$ & $10(2.1)$ & - & $>.999^{*}$ \\
\hline & & None & $503(98.1)$ & $36(100.0)$ & $467(97.9)$ & & \\
\hline & Dobutamine & Yes & $21(4.1)$ & $4(11.1)$ & $17(3.6)$ & - & $.052^{*}$ \\
\hline & & None & $492(95.9)$ & $32(88.9)$ & $460(96.4)$ & & \\
\hline & Umbilical venous catheter & Yes & $472(92.0)$ & $33(91.7)$ & $438(91.8)$ & - & $>.999^{*}$ \\
\hline & & None & $41(8.0)$ & $3(8.3)$ & $39(8.2)$ & & \\
\hline & Umbilical arterial catheter & Yes & $68(13.3)$ & $16(44.4)$ & $52(10.9)$ & - & $<.001^{*}$ \\
\hline & & None & $445(86.7)$ & $20(55.6)$ & $425(89.1)$ & & \\
\hline & PICC, NCV & Yes & $464(90.4)$ & $33(91.7)$ & $431(90.4)$ & - & $>.999^{*}$ \\
\hline & & None & $49(9.6)$ & $3(8.3)$ & $46(9.6)$ & & \\
\hline Mothers & Delivery type & Spontaneous & $79(15.4)$ & $6(16.7)$ & $73(15.3)$ & 0.05 & .827 \\
\hline & & C-sec & $434(84.6)$ & $30(83.3)$ & $404(84.7)$ & & \\
\hline & Infectious disease of the mother & Yes & $132(25.7)$ & $13(36.1)$ & $119(24.9)$ & 2.18 & .140 \\
\hline & & None & $381(74.3)$ & $23(63.9)$ & $358(75.1)$ & & \\
\hline & Premature rupture of membranes/ & Yes & $193(37.6)$ & $18(50.0)$ & $175(36.7)$ & 2.53 & .112 \\
\hline & amniotic fluid leakage & None & $320(62.4)$ & $18(50.0)$ & $302(63.3)$ & & \\
\hline & Pre-eclampsia & Yes & $87(17.0)$ & $8(22.2)$ & 79 (16.6) & 0.76 & .383 \\
\hline & & None & $426(83.0)$ & $28(77.8)$ & $398(83.4)$ & & \\
\hline & Disorder of amniotic fluid & Yes & $28(5.5)$ & $5(13.9)$ & $23(4.8)$ & - & $.038^{*}$ \\
\hline & volume $^{\dagger}$ & None & $485(94.5)$ & $31(86.1)$ & $454(95.2)$ & & \\
\hline & Placenta-related complications & Yes & $48(9.4)$ & $1(2.8)$ & 47 (9.9) & - & $.235^{*}$ \\
\hline & & None & 465 (90.6) & 35 (97.2) & 430 (90.1) & & \\
\hline
\end{tabular}

${ }^{*}$ Fisher exact test; ${ }^{\dagger}$ Polyhydramnios, oligohydramnios; C-sec, cesarean section; MBP, mean blood pressure; NCV, neonatal central vein; PICC, peripherally inserted central catheter. 
Table 2. Differences in the Health Status of Premature Newborns with or without Peripheral Arterial Ischemia $(N=513)$

\begin{tabular}{|c|c|c|c|c|c|}
\hline \multirow{3}{*}{ Variables } & \multirow{3}{*}{ Categories } & \multicolumn{2}{|c|}{ Peripheral arterial ischemia } & \multirow{3}{*}{$\mathrm{t}$} & \multirow{3}{*}{$p$} \\
\hline & & Yes $(n=36)$ & None $(n=477)$ & & \\
\hline & & $\mathrm{M} \pm \mathrm{SD}$ & $\mathrm{M} \pm \mathrm{SD}$ & & \\
\hline \multirow[t]{2}{*}{ Apgar score } & 1-min & $2.61 \pm 1.95$ & $4.23 \pm 2.02$ & 4.63 & $<.001$ \\
\hline & 5 -min & $4.69 \pm 2.07$ & $6.47 \pm 1.88$ & 5.42 & $<.001$ \\
\hline \multirow{11}{*}{ Laboratory tests } & $\mathrm{pH}$ & $7.21 \pm 0.10$ & $7.30 \pm 0.11$ & 4.90 & $<.001$ \\
\hline & $\mathrm{CO}_{2}(\mathrm{mmHg})$ & $53.24 \pm 16.38$ & $44.81 \pm 12.28$ & 3.02 & .004 \\
\hline & $\mathrm{BE}(\mathrm{mmol} / \mathrm{L})$ & $-6.19 \pm 4.59$ & $-4.22 \pm 3.69$ & 3.02 & .003 \\
\hline & Hemoglobin (g/dL) & $14.67 \pm 3.09$ & $15.57 \pm 2.59$ & 1.99 & .047 \\
\hline & Hematocrit (\%) & $43.41 \pm 8.59$ & $45.65 \pm 7.13$ & 1.79 & .074 \\
\hline & Platelet (109/L) & $182.56 \pm 81.92$ & $219.16 \pm 70.82$ & 2.96 & .003 \\
\hline & $\mathrm{CRP}(\mathrm{mg} / \mathrm{dL})$ & $0.21 \pm 0.74$ & $0.18 \pm 0.75$ & 0.21 & .830 \\
\hline & AST (U/L) & $50.83 \pm 68.64$ & $45.46 \pm 99.75$ & 0.32 & .751 \\
\hline & ALT (U/L) & $15.67 \pm 42.09$ & $8.08 \pm 18.45$ & 1.07 & .290 \\
\hline & $\mathrm{LDH}(\mathrm{mg} / \mathrm{dL})$ & $1,033.17 \pm 656.28$ & $975.75 \pm 644.70$ & 0.51 & .607 \\
\hline & $\mathrm{CPK}(\mathrm{mg} / \mathrm{dL})$ & $152.47 \pm 115.65$ & $218.59 \pm 188.53$ & 2.07 & .039 \\
\hline \multirow[t]{5}{*}{ Duration of inotropic agents (day) } & Dopamine & $8.89 \pm 7.41$ & $1.97 \pm 5.65$ & 5.48 & $<.001$ \\
\hline & Vasopressin & $4.81 \pm 6.22$ & $0.80 \pm 2.94$ & 3.83 & $<.001$ \\
\hline & Epinephrine & $2.25 \pm 4.61$ & $0.30 \pm 1.54$ & 2.53 & .016 \\
\hline & Norepinephrine & $0.00 \pm 0.00$ & $0.08 \pm 0.71$ & 0.71 & .478 \\
\hline & Dobutamine & $0.97 \pm 3.33$ & $0.14 \pm 0.84$ & 1.50 & .142 \\
\hline Duration of ventilator care (day) & & $6.39 \pm 1.54$ & $3.53 \pm 2.81$ & 9.97 & $<.001$ \\
\hline \multirow{2}{*}{ Umbilical venous catheter (day) } & Insertion day & $0.92 \pm 0.28$ & $0.95 \pm 0.44$ & 0.45 & .655 \\
\hline & Duration & $5.86 \pm 4.70$ & $3.79 \pm 2.91$ & 2.60 & .013 \\
\hline \multirow[t]{2}{*}{ Umbilical arterial catheter (day) } & Insertion day & $0.44 \pm 0.50$ & $0.11 \pm 0.31$ & 3.94 & $<.001$ \\
\hline & Duration & $4.22 \pm 6.05$ & $0.63 \pm 2.13$ & 3.55 & .001 \\
\hline \multirow[t]{2}{*}{ PICC, NCV (day) } & Insertion day & $5.00 \pm 4.42$ & $3.44 \pm 3.44$ & 2.07 & .046 \\
\hline & Duration & $19.00 \pm 12.32$ & $16.86 \pm 11.33$ & 1.09 & .278 \\
\hline \multirow[t]{2}{*}{ Apnea onset (day) } & Onset & $1.50 \pm 1.99$ & $1.39 \pm 1.86$ & 0.34 & .734 \\
\hline & Duration & $1.11 \pm 1.33$ & $1.14 \pm 1.70$ & 0.11 & .914 \\
\hline
\end{tabular}

ALT, alanine aminotransferase; AST, aspartate aminotransferase; $\mathrm{BE}$, base excess; CO2, carbon dioxide; CPK, creatine phosphokinase; CRP, C-reactive protein; $\mathrm{LDH}$, lactate dehydrogenase; $\mathrm{NCV}$, neonatal central vein; $\mathrm{pH}$, potential of hydrogen; PICC, peripherally inserted central catheter.

applied at 0.03 days after onset on average for newborns without necrosis and at 10.5 days after onset for those with necrosis. Newborns without necrosis showed improvement at 4.32 days after the application of nitroglycerin patches on average, while those with necrosis showed improvement at 7.50 days after application; although the area of necrosis disappeared, there was no statistically significant difference. It was not possible to quickly apply nitroglycerin patches in two infants because of uncorrected hypotension and oliguria. Dopamine was administered to premature newborns with only ischemia for an average of 8.32 days, while it was administered for 18.5 days in those with necrosis; although this was a difference of over 10 days, it was not statistically significant. There was no difference in the use of vasopressin and epinephrine according to the incidence of necrosis, but a significant difference was found in dobutamine use, which was used for 0.71 days in premature newborns with only ischemia on average and 5.50 days in those with necrosis ( $\mathrm{U}=65.0, p=.019)$. There was no significant difference in the duration of umbilical arterial catheter use.

\section{Factors Influencing the Occurrence of Peripheral Ar- terial Ischemia}

Logistic regression analysis was conducted to identify factors related to the occurrence of peripheral arterial ischemia. The dependent variable was the incidence of peripheral arterial ischemia, and the independent variable was the treatments received by premature infants. The results of the univariate logistic regression analysis are summarized in Table 4.

Gestational age was negatively associated with effective peripheral arterial ischemia (odds ratio $[\mathrm{OR}]=0.95,95 \%$ con- 
Table 3. Occurrence of Necrosis in Premature Newborns with Peripheral Arterial Ischemia $(N=36)$

\begin{tabular}{|c|c|c|c|c|}
\hline \multirow{3}{*}{ Variables } & \multicolumn{2}{|c|}{ Necrosis } & \multirow{3}{*}{$U^{*}$} & \multirow{3}{*}{$p$} \\
\hline & Yes $(n=2)$ & None $(n=34)$ & & \\
\hline & $\mathrm{M} \pm \mathrm{SD}$ & $\mathrm{M} \pm \mathrm{SD}$ & & \\
\hline Onset day of necrosis after ischemia & $13.00 \pm 8.49$ & & & \\
\hline Onset day of ischemia (day) & $19.00 \pm 5.66$ & $3.15 \pm 4.58$ & 66.0 & .013 \\
\hline Nitroglycerin patch application after ischemia (day) & $10.50 \pm 14.85$ & $0.03 \pm 0.17$ & 50.5 & .286 \\
\hline Improvement date after nitroglycerin patches application (day) & $7.50 \pm 3.54$ & $4.32 \pm 3.12$ & 56.5 & .133 \\
\hline \multicolumn{5}{|l|}{ Average booster use date (day) } \\
\hline Dopamine & $8.32 \pm 7.19$ & $18.50 \pm 4.95$ & 59.0 & .095 \\
\hline Vasopressin & $4.79 \pm 6.29$ & $5.00 \pm 7.07$ & 34.0 & $>.999$ \\
\hline Epinephrine & $2.24 \pm 4.70$ & $2.50 \pm 3.54$ & 40.0 & .714 \\
\hline Dobutamine & $0.71 \pm 3.12$ & $5.50 \pm 4.95$ & 65.0 & .019 \\
\hline Average maintenance period of umbilical arterial catheter & $12.50 \pm 2.12$ & $5.47 \pm 4.53$ & 61.5 & .051 \\
\hline
\end{tabular}

*Mann-Whitney U test.

Table 4. Factors Influencing the Occurrence of Peripheral Arterial Ischemia $(N=36)$

\begin{tabular}{|c|c|c|c|c|c|c|c|c|}
\hline \multirow{2}{*}{ Variables } & \multirow{2}{*}{ B } & \multirow{2}{*}{ SE } & \multirow{2}{*}{ Wald } & \multirow{2}{*}{ df } & \multirow{2}{*}{$p$} & \multirow{2}{*}{ OR } & \multicolumn{2}{|c|}{$95 \% \mathrm{CI}$} \\
\hline & & & & & & & Minimum & Maximum \\
\hline Gestational age (week) & -0.05 & 0.09 & 37.10 & 1 & $<.001$ & 0.95 & 0.93 & 0.97 \\
\hline Birth weight $(\mathrm{g})$ & -0.02 & 0.00 & 26.03 & 1 & $<.001$ & 0.99 & 0.98 & 1.00 \\
\hline 1-min Apgar score & -0.42 & 0.10 & 18.20 & 1 & $<.001$ & 0.66 & 0.54 & 0.80 \\
\hline 5-min Apgar score & -0.42 & 0.08 & 24.53 & 1 & $<.001$ & 0.66 & 0.56 & 0.78 \\
\hline Patent ductus arteriosus & 1.33 & 0.45 & 8.66 & 1 & .003 & 3.77 & 1.56 & 9.13 \\
\hline Use of inotropic agents (day) & 2.01 & 0.39 & 27.11 & 1 & $<.001$ & 7.48 & 3.51 & 15.96 \\
\hline Duration of ventilator care (day) & 0.56 & 0.12 & 21.27 & 1 & $<.001$ & 1.75 & 1.38 & 2.22 \\
\hline In-dwelling umbilical arterial lines (day) & 1.88 & 0.37 & 26.30 & 1 & $<.001$ & 6.54 & 3.20 & 13.40 \\
\hline
\end{tabular}

$\mathrm{df}$, degrees of freedom; OR, odds ratio; CI, confidence interval.

fidence interval $[\mathrm{CI}]=0.93-0.97, p<.001)$, indicating that an increase in gestational age of 1 week was associated with a 0.95 times reduction in the likelihood of peripheral arterial ischemia. Birth weight was negatively associated with effective peripheral arterial ischemia (OR=0.99, 95\% CI=0.98-1.00, $p<$ $.001)$, indicating that an increase in birth weight of $1 \mathrm{~g}$ was associated with a 0.99 times reduction in the likelihood of peripheral arterial ischemia. The 1-minute Apgar score was negatively associated with effective peripheral arterial ischemia (OR=0.66, 95\% CI=0.54-0.80, $p<.001$ ), with a 1-point increase in the 1-minute Apgar score associated with a 0.66 times lower risk of peripheral arterial ischemia. The 5-minute Apgar score was negatively associated with effective peripheral arterial ischemia $(\mathrm{OR}=0.66,95 \% \mathrm{CI}=0.56-0.78, p<.001)$, showing that a 1-point increase in the 5-minute Apgar score was associated with a 0.66 times lower risk of peripheral arterial ischemia.

Patent ductus arteriosus (PDA) was positively associated with peripheral arterial ischemia $(\mathrm{OR}=3.77,95 \% \mathrm{CI}=1.56-9.13$, $p=.003$ ), indicating that infants with PDA were 3.77 times more likely to develop ischemia than newborns without PDA. The duration of inotropic agent use was positively associated with peripheral arterial ischemia $(\mathrm{OR}=7.48,95 \% \mathrm{CI}=3.51$ $15.96, p<.001$ ), and an increase in the duration of inotropic agent use of 1 day was associated with a 7.48 times higher likelihood of peripheral arterial ischemia. Duration of ventilator care was positively associated with peripheral arterial ischemia $(\mathrm{OR}=1.75,95 \% \mathrm{CI}=1.38-2.22, p<.001)$, with a 1 -day increase in the duration of ventilator care associated with a 1.75 
times higher risk of peripheral arterial ischemia. The duration of in-dwelling umbilical arterial catheter use was positively associated with peripheral arterial ischemia (OR=6.54, 95\% $\mathrm{CI}=3.20-13.40, p<.001)$, as each 1-day increase in in-dwelling umbilical arterial catheter time was associated with a 6.54 times higher likelihood of peripheral arterial ischemia.

\section{Effects of Nitroglycerin Patch Application}

Among the preterm infants in whom a nitroglycerin patch was applied, $30(83.3 \%)$ infants without necrosis improved without complications, four (11.1\%) showed hypotension, and two $(5.6 \%)$ showed skin damage.

The time needed for improvement was less than 2 days for nine $(25.0 \%)$ newborns, between 3 and 6 days for 21 (58.3\%) newborns, and more than 7 days for six (16.7\%) newborns, indicating that most improved to a significant degree within 7 days. One of the premature newborns with necrosis lost the tips of finger but healed in areas without necrosis, while another infant died and ongoing treatment results could not be observed. Of the 34 infants with ischemia without necrosis, 14 $(41.2 \%)$ died. The mortality rate of neonates with peripheral arterial ischemia was high.

\section{DISCUSSION}

This study analyzed the characteristics affecting the incidence of peripheral arterial ischemia and tissue necrosis in premature newborns, as well as the effects of nitroglycerin patches. It was found that newborns with peripheral arterial ischemia had a significantly lower gestational age and birth weight, aligning with the findings of Mourot et al. [19], who reported that infants with a lower weight and age had more ischemic complications. This finding also agrees with the results of Troiani et al. [1], who reported that premature newborns with respiratory distress syndrome developed difficulties in micro-vessel expansion and circulation and that lower gestational age, weight, and Apgar scores were significantly associated with the severity of this problem. The logistic analysis showed that the factors affecting peripheral arterial ischemia were lower gestational age, lower birth weight, lower 1-minute Apgar scores, lower 5-minute Apgar scores, occurrence of PDA, the duration of inotropic agent use, the duration of ventilator treatment, and the duration of in-dwelling umbilical arterial lines. The factors affecting peripheral arterial ischemia were the duration of umbilical artery catheterization, which was also identified as a cause of peripheral arterial ischemia by Teo and Shah [20], Rizzi et al. [21], and Han et al. [9]. In the study of Samiee-Zafarghandy et al. [8], a low Apgar score, lower gestational age (26+4 weeks), and ven- tilator treatment were also identified as significant factors, as in this study.

In addition, as described by Saxonhouse [22], the presence of risk factors for blood clots and embolisms such as PDA (a congenital heart disease), ventilator use duration (an indicator of respiratory distress), the use of umbilical arterial catheters as central venous catheters, and pulmonary hypertension also demonstrated significant differences, as in this study. Kamar et al. [2] reported a higher likelihood of peripheral arterial ischemia in newborns due to the influence of vasoconstrictive hormones in mothers with high blood pressure, but the present study showed no connection between the incidence of peripheral arterial ischemia in newborns and maternal preeclampsia.

This study found a significant difference in the use of inotropic agents, similar to the findings of domestic and international studies on limb necrosis due to vasoconstrictive agents and inotropic agents $[23,24]$. Blood pressure was measured on the third day after birth, after 72 hours when the PDA was closed; it was found that the blood pressure of premature newborns with peripheral arterial ischemia was significantly more likely to be in the 50th percentile or lower. This result confirmed that low blood pressure can cause vasospasms and thrombosis, and consequently peripheral arterial ischemia and skin necrosis [25]. Premature newborns commonly experience low blood pressure due to treatment of their conditions and surgery, and very premature newborns commonly experience shock in the early neonatal period. Vasoconstrictors and inotropic agents are commonly used to ameliorate the decline in mean blood pressure and the reduction of renal perfusion in patients who are hemodynamically unstable due to shock and systemic hypotension [12]. Dopamine and dobutamine (inotropic agents) are used in the early postnatal period to treat shock in newborns. If whole-body circulation does not improve despite the use of drugs, it may be necessary to continue the use of vasoconstrictors and inotropic agents in large quantities. However, the continuing application of vasoconstrictors and inotropic agents in large doses may cause hypodermic tissue ischemia and peripheral vasoconstriction, and ultimately, tissue necrosis [26-28].

Because premature newborns have a smaller vein diameter and a higher risk of poor circulation [5], the long-term use of vasoconstrictors and inotropic agents increased the chances of peripheral arterial ischemia especially strongly in premature newborns. This aligns with the results of earlier domestic and international studies [20,21], which found that umbilical arterial catheters and umbilical venous catheters may cause the formation of blood clots as well as peripheral vasospasms and peripheral arterial ischemia.

In the cases reported by Kamar et al. [2], a 2\% nitroglycerin 
spray was applied on areas with tissue necrosis resulting from peripheral arterial ischemia every 8 hours for 2 weeks, and it was found that the temperature of the area of skin with tissue necrosis rose and that capillary circulation in the hands and feet became normal [5]. A 2\% nitroglycerin ointment was applied on the skin of premature newborns with tissue necrosis in quantities of $4 \mathrm{~mm} / \mathrm{kg}$ ribbon every 8 hours until their condition improved; Samiee-Zafarghandy et al. [8] also applied the same amount every 6 hours for 2 weeks.

Surmising that the risk of amputation is higher when the tissue ischemia is more extensive and the degree of necrosis is more severe, additional treatment besides local application of nitroglycerin ointment may be needed in patients with serious symptoms. All the studies described above reported that the application of nitroglycerin medication was followed by improvements in peripheral arterial ischemia and circulation of areas with necrosis, restoration of skin color, and recovery of the skin, except in areas of partial loss [2,5,8-11,13,14].

In this study, it was also found that the application of nitroglycerin patches in premature newborns with peripheral arterial ischemia resulted in improvements in $83.3 \%$ of patients. Specifically, premature newborns without necrosis showed improvement within an average of 4.32 days and those with necrosis showed improvement within an average of 7.50 days, indicating that patches led to faster improvements than the 2 weeks needed for improvements in response to ointments in earlier studies [9].

Although we did not find a significant association between the length of dobutamine use and peripheral arterial ischemia incidence, a significant relationship was found between dobutamine and the incidence of necrosis, which we surmise to have resulted from the fact that dobutamine was selectively used in premature newborns with necrosis due to dobutamine's characteristic of weakening vascular resistance and its greater ability to improve blood flow volume than dopamine [29]. Premature newborns with peripheral arterial ischemia who did not have necrosis exhibited complete healing in response to nitroglycerin patch treatment, which aligns with the results of earlier studies [2,5,8,11].

Peripheral arterial ischemia and necrosis threaten the survival of premature newborns. Earlier studies have reported that peripheral arterial ischemia due to congenital ischemia can occur immediately after birth for reasons such as placental ischemia and is difficult to treat effectively [30]. Thus, it is difficult to conclude that nitroglycerin patches would be effective in treating all cases. However, nitroglycerin patch treatment can be attempted considering the possibility of improvement and the fact that it has few complications, since losing fingers and toes is permanent damage. In addition, premature newborns with high risk factors for peripheral arterial ische- mia should be monitored closely.

\section{CONCLUSION}

This study identified factors affecting the incidence of peripheral arterial ischemia by analyzing the characteristics of premature newborns based on a review of EMRs, and also investigated the effects of applying nitroglycerin patches. Premature newborns were more likely to experience peripheral arterial ischemia when they had a lower gestational age and weight. The incidence of peripheral arterial ischemia was higher in newborns with low Apgar scores and blood gas results indicating respiratory acidosis, as well as in those with low hemoglobin levels and platelet count and those who had received ventilator treatment.

Furthermore, the likelihood of peripheral arterial ischemia incidence was higher in premature newborns in whom inotropic agents were used or umbilical arterial catheters were inserted. Although minimal handling is important in nursing premature newborns, it is expected that these research findings will assist clinicians in recognizing the characteristics of infants at high risk for peripheral arterial ischemia and lead to more careful inspections and care of the skin for premature newborns with a high risk of developing peripheral arterial ischemia.

In addition, this study reconfirmed the importance of applying nitroglycerin patches to premature newborns with peripheral arterial ischemia as soon as possible, as well as the importance of studying their prognosis. Peripheral tissue injuries are a well-described source of iatrogenic morbidity associated with NICU stays in newborns. Peripheral tissue injuries can potentially lead to complete necrosis and loss of the affected limb. Therefore, nurses should be aware of the nature of the occurrence of peripheral arterial ischemia and provide care that closely assesses the peripheral circulation in premature infants. It is expected that this study will help establish a more specific and systematic protocol that can be applied to clinical nursing.

This research has limitations in the generalizability of its findings, because it only studied infants treated in two NICUs at the same institution and the geographic distribution of premature newborns was not uniform. Due to ethical issues, the NICUs did not have many premature newborns with tissue necrosis caused by peripheral arterial ischemia who did not receive nitroglycerin treatment, so it was difficult to make comparisons. There were only two premature newborns with necrosis, so it was impossible to conduct logistic regression statistics of these patients. Thus, we suggest that future studies should compare nitroglycerin patches with ointment. 


\section{Conflict of interest}

No existing or potential conflict of interest relevant to this article was reported.

\section{Data availability}

Please contact the corresponding author for data availability.

\section{REFERENCES}

1. Troiani S, Cardona A, Milioni M, Monacelli D, Verrotti A, Gehring $\mathrm{M}$, et al. Evidence of impaired microvascular dilatation in preterms with acute respiratory distress syndrome. International Journal of Cardiology. 2017;241:83-86.

https://doi.org/10.1016/j.ijcard.2017.04.018

2. Kamar R, van Vonderen JJ, Lopriore E, Te Pas AB. Nitroglycerin for severe ischaemic injury after peripheral arterial line in a preterm infant. Acta Paediatrica. 2013;102(4):e144-e145.

https://doi.org/10.1111/apa.12141

3. Visscher MO, Adam R, Brink S, Odio M. Newborn infant skin: Physiology, development, and care. Clinics in Dermatology. 2015; 33(3):271-280. https://doi.org/10.1016/j.clindermatol.2014.12.003

4. Oranges T, Dini V, Romanelli M. Skin physiology of the neonate and infant: Clinical implications. Advances in Wound Care. 2015; 4(10):587-595. https://doi.org/10.1089/wound.2015.0642

5. Mosalli R, Elbaz M, Paes B. Topical nitroglycerine for neonatal arterial associated peripheral ischemia following cannulation: A case report and comprehensive literature review. Case Report in Pediatrics. 2013;2013:608516.

https://doi.org/10.1155/2013/608516

6. Saracco P, Bagna R, Gentilomo C, Magarotto M, Viano A, Magnetti $\mathrm{F}$, et al. Clinical data of neonatal systemic thrombosis. Journal of Pediatrics. 2016;171:60-66. https://doi.org/10.1016/j.jpeds.2015.12.035

7. Piersigilli F, Bersani I, Giliberti P, Ronchetti MP, Mancinelli RL, Cavadenti I, et al. Neonatal limb ischemia: Caudal blockade and NIRS monitoring. European Journal of Pediatrics. 2014;173(12): 1599-1601. https://doi.org/10.1007/s00431-013-2152-y

8. Samiee-Zafarghandy S, van den Anker JN, Ben Fadel N. Topical nitroglycerin in neonates with tissue injury: A case report and review of the literature. Paediatrics and Child Health. 2014;19(1):9-12. https://doi.org/10.1093/pch/19.1.9

9. Han YS, Song S, Sung TJ, Chun J. Successful management of severe peripheral tissue ischemia after arterial catheterization in micro preemies using humidification and topical nitroglycerin. Neonatal Medicine. 2017;24(4):197-201. https://doi.org/10.5385/nm.2017.24.4.197

10. Kleydman K, Cohen JL, Marmur E. Nitroglycerin: A review of its use in the treatment of vascular occlusion after soft tissue augmen- tation. Dermatologic Surgery. 2012;38(12):1889-1897.

https://doi.org/10.1111/dsu.12001

11. Geffroy-Perrin C, Geffroy C, Gentili ME. Application of nitroglycerin patch to treat finger cyanosis due to unintentional injection of epinephrine. American Journal of Emergency Medicine. 2017;35(2): 372.e5-372.e6. https://doi.org/10.1016/j.ajem.2016.07.051

12. Gomella TL, Cunningham MD, Eyal FG, Zenk KE. Neonatology: Management, procedures, on-call problems, diseases, and drugs. 7th ed. New York, NY: McGraw-Hill Medical; 2013. p. 89-97, 537-546.

13. Vivar del Hoyo P, Sánchez Ruiz P, Ludeña del Río M, López-Menchero Oliva JC, García Cabezas MÁ. Use of topical nitroglycerin in newborns with ischaemic injuries after vascular cannulation. Anales de Pediatría (English Edition). 2016;85(3):155-156. https://doi.org/10.1016/j.anpede.2016.01.006

14. Colmenero CG, Garcia EM, Morente GB, Sánchez JT. Nitroglycerin patch for the treatment of chondrodermatitis nodularis helicis: A new therapeutic option. Dermatologic Therapy. 2014;27(5):278-280. https://doi.org/10.1111/dth.12137

15. Sung SI, Ahn SY, Seo HJ, Yoo HS, Han YM, Lee MS, et al. Insensible water loss during the first week of life of extremely low birth weight infants less than 25 gestational weeks under high humidification. Neonatal Medicine. 2013;20(1):51-57. https://doi.org/10.5385/nm.2013.20.1.51

16. Tonnus W, Meyer C, Paliege A, Belavgeni A, von Massenhausen A, Bornstein SR, et al. The pathological features of regulated necrosis. Journal of Pathology. 2019;247(5):697-707. https://doi.org/10.1002/ path.5248

17. Albahrani Y, Hunt R. Newborn skin care. Pediatrics Annals. 2019;48 (1):e11-e15. https://doi.org/10.3928/19382359-20181211-01

18. Dionne JM, Abitbol CL, Flynn JT. Hypertension in infancy: Diagnosis, management and outcome. Pediatric Nephrology. 2012;27 (1):17-32. https://doi.org/10.1007/s00467-010-1755-z

19. Mourot JM, Oliveira HM, Woodson LC, Herndon DN, Chung DH. Complications of femoral artery catheterization in pediatric burn patients. Journal of Burn Care and Research. 2009;30(3):432-436. https://doi.org/10.1097/BCR.0b013e3181a28c6e

20. Teo MC, Shah VA. Digital ischaemia following inadvertent arterial cannulation of a peripherally inserted central catheter in a very low birth weight infant. Singapore Medical Journal. 2015;56(8):482-483. https://doi.org/10.11622/smedj.2015125

21. Rizzi M, Goldenberg N, Bonduel M, Revel-Vilk S, Amankwah E, Albisetti M. Catheter-related arterial thrombosis in neonates and children: A systematic review. Thrombosis and Haemostasis. 2018; 118(6):1058-1066. https://doi.org/10.1055/s-0038-1642635

22. Saxonhouse MA. Management of neonatal thrombosis. Clinics in Perinatology. 2012;39(1):191-208. https://doi.org/10.1016/j.clp.2011.12.018

23. Kwon JW, Hong MK, Park BY. Risk factors of vasopressor-induced symmetrical peripheral gangrene. Annals of Plastic Surgery. 2018; 80(6):622-627. https://doi.org/10.1097/sap.0000000000001314 
24. Dong J, Zhang L, Rao G, Zhao X. Complicating symmetric peripheral gangrene after dopamine therapy to patients with septic shock. Journal of Forensic Sciences. 2015;60(6):1644-1646.

https://doi.org/10.1111/1556-4029.12844

25. Kumar J, Dutta S, Sundaram V, Saini SS, Sharma RR, Varma N. Platelet transfusion for PDA closure in preterm infants: A randomized controlled trial. Pediatrics. 2019;143(5):e20182565.

https://doi.org/10.1542/peds.2018-2565

26. Pacifici GM. Clinical pharmacology of dobutamine and dopamine in preterm neonates. Medical Express. 2014;1(5):275-283. https://doi.org/10.5935/MedicalExpress.2014.05.12

27. Bhat BV, Plakkal N. Management of shock in neonates. Indian Journal of Pediatrics. 2015;82(10):923-929.

https://doi.org/10.1007/s12098-015-1758-7
28. Arnáiz-García ME, Arnáiz-García AM, Gutiérrez-Diez JF, González-Santos JM, García-Martín A, Alonso-Peña D, et al. Vasopressor-induced peripheral skin necrosis after shock. Revista Portuguesa de Cardiologia (English Edition). 2017;36(7-8):573-574. https://doi.org/10.1016/j.repce.2016.07.010

29. Eley KA, Young JD, Watt-Smith SR. Epinephrine, norepinephrine, dobutamine, and dopexamine effects on free flap skin blood flow. Plastic and Reconstructive Surgery. 2012;130(3):564-570. https://doi.org/10.1097/PRS.0b013e31825dbf73

30. Onalo R, Ogala WN, Lawal YZ, Chom ND, Odogu O, Ige SO. Congenital gangrene of the extremities in a newborn. Nigerian Journal of Clinical Practice. 2011;14(2):245-248.

https://doi.org/10.4103/1119-3077.84031 